\title{
Paired inspiratory-expiratory chest CT scans to assess for small airways disease in COPD
}

\author{
Craig P Hersh ${ }^{1,2^{*}}$, George R Washko ${ }^{2}$, Raúl San José Estépar², Sharon Lutz ${ }^{3}$, Paul J Friedman ${ }^{5}$, MeiLan K Han ${ }^{6}$, \\ John E Hokanson ${ }^{4}$, Philip F Judy ${ }^{7}$, David A Lynch ${ }^{8}$, Barry J Make ${ }^{9}$, Nathaniel Marchetti ${ }^{10}$, John D Newell Jr ${ }^{11}$, \\ Frank C Sciurba ${ }^{12}$, James D Crapo ${ }^{9}$, Edwin K Silverman ${ }^{1,2}$ and The COPDGene Investigators
}

\begin{abstract}
Background: Gas trapping quantified on chest CT scans has been proposed as a surrogate for small airway disease in COPD. We sought to determine if measurements using paired inspiratory and expiratory CT scans may be better able to separate gas trapping due to emphysema from gas trapping due to small airway disease.

Methods: Smokers with and without COPD from the COPDGene Study underwent inspiratory and expiratory chest CT scans. Emphysema was quantified by the percent of lung with attenuation $<-950 \mathrm{HU}$ on inspiratory $\mathrm{CT}$. Four gas trapping measures were defined: (1) Exp ${ }_{-856}$, the percent of lung <-856 HU on expiratory imaging; (2) E/l MLA, the ratio of expiratory to inspiratory mean lung attenuation; (3) $R V C_{856-950}$, the difference between expiratory and inspiratory lung volumes with attenuation between -856 and $-950 \mathrm{HU}$; and (4) Residuals from the regression of Exp_-856 on percent emphysema.
\end{abstract}

Results: In 8517 subjects with complete data, Exp_-856 was highly correlated with emphysema. The measures based on paired inspiratory and expiratory CT scans were less strongly correlated with emphysema. Exp_-856, E/I MLA and RVC $_{856-950}$ were predictive of spirometry, exercise capacity and quality of life in all subjects and in subjects without emphysema. In subjects with severe emphysema, E/I MLA and RVC $856-950$ showed the highest correlations with clinical variables.

Conclusions: Quantitative measures based on paired inspiratory and expiratory chest $C T$ scans can be used as markers of small airway disease in smokers with and without COPD, but this will require that future studies acquire both inspiratory and expiratory $C T$ scans.

Keywords: Emphysema, Chest CT scan, Small airways, Lung function tests, Smoking

\section{Introduction}

The small airways $(<2 \mathrm{~mm}$ diameter) are the predominant site of airflow limitation in chronic obstructive pulmonary disease (COPD) [1]. Emphysema and large airway disease, two other major pathologies in COPD, can be visualized using chest CT scans. However, the small airways cannot be directly imaged using current CT scan technology [2]. Traditionally, gas trapping on pulmonary function testing, based on the ratio of either residual volume (RV) or inspiratory capacity to total lung capacity (TLC), has been

\footnotetext{
* Correspondence: craig.hersh@channing.harvard.edu

${ }^{1}$ Channing Division of Network Medicine, Brigham and Women's Hospital and Harvard Medical School, 181 Longwood Avenue, Boston, MA 02115, USA ${ }^{2}$ Division of Pulmonary and Critical Care Medicine, Brigham and Women's Hospital and Harvard Medical School, Boston, MA, USA

Full list of author information is available at the end of the article
}

used as a surrogate for small airway disease. Given the marked heterogeneity among COPD subjects and the increasingly widespread use of chest CT scans in smokers with and without COPD [3], there is a need to identify an accurate marker of small airway disease on chest CT scans, which may complement measures of small airway disease derived from traditional lung function testing. The percent of lung voxels with attenuation below a specific threshold, such as -856 Hounsfield units (HU), on expiratory chest CT scans has been proposed as an indicator for gas trapping in subjects with asthma [4]. In subjects with COPD, this threshold method fails to distinguish gas trapping due to emphysema from gas trapping due to small airway disease (Figure 1).

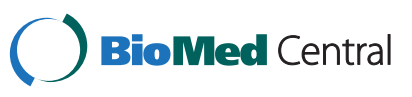




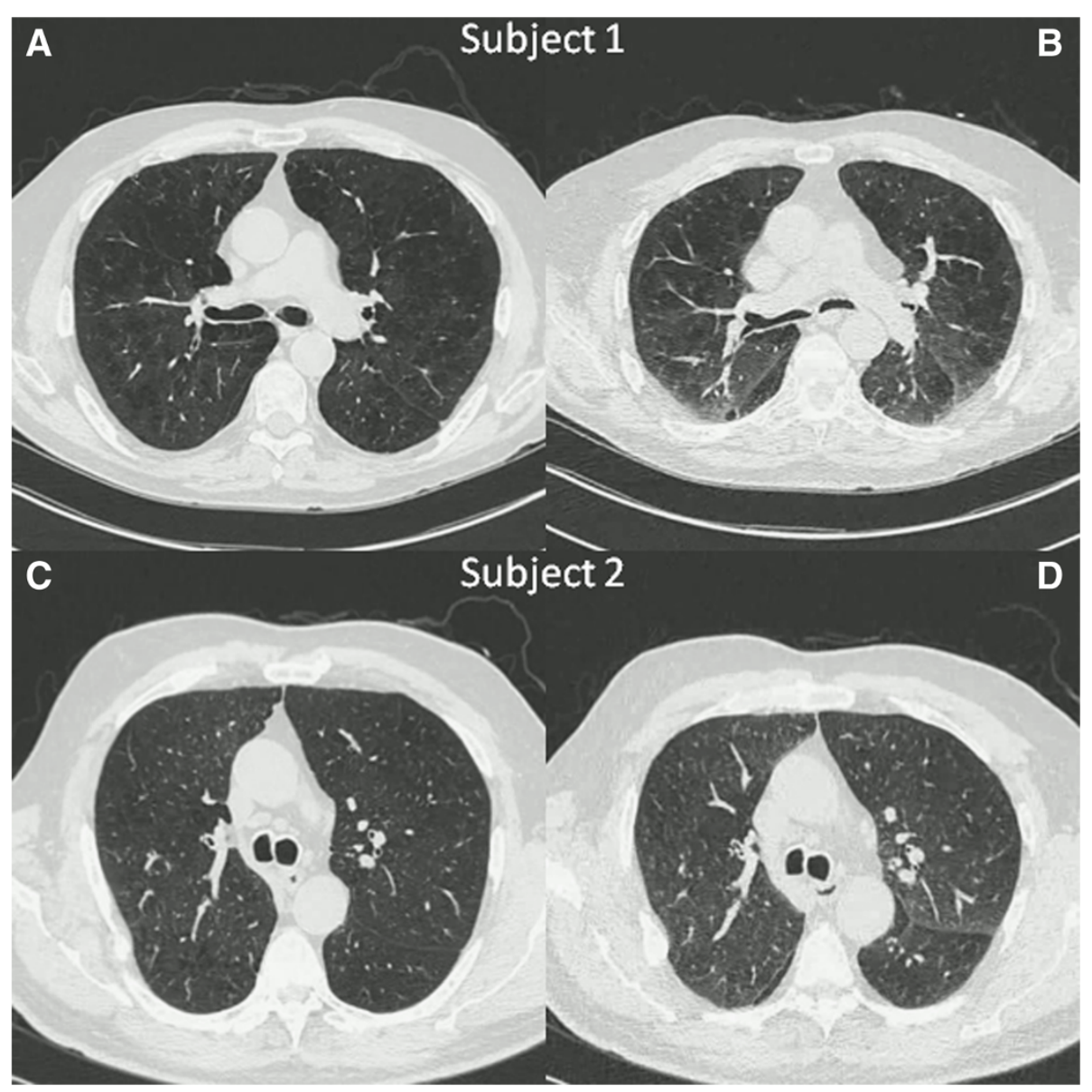

Figure 1 Inspiratory $(A, C)$ and expiratory $(B, D)$ chest $C T$ images from two subjects with similar percent of lung voxels with attenuation values $<-856 \mathrm{HU}$ on expiratory CT scans $\left(\operatorname{Exp}_{-856}\right.$ ) demonstrate the inability of expiratory image analysis alone to distinguish gas trapping due to emphysema from gas trapping due to small airway disease. Subject 1: Exp_-856 $=38.5 \%$, percent emphysema

$\left(\operatorname{Insp}_{-950}\right)=23.1 \%$. Subject 2: $\operatorname{Exp}_{-856}=37.1 \%$, Insp-950 $=6.9 \%$.

Several alternative gas trapping measures have been proposed in subjects with COPD based on quantitative CT analysis [5-10]. These prior studies have generally had limited sample sizes, with few subjects with either normal lung function or severe COPD. Differentiation of gas trapping due to small airway disease from emphysematous gas trapping is especially important in subjects with more severe COPD, who generally have more emphysema. A recently published lung cancer screening study from the Netherlands included inspiratory and expiratory chest CT scans on a large sample of control smokers and subjects with COPD, showing the independent ability of CT emphysema and CT gas trapping measures to predict COPD status defined by spirometry [11]. However, COPD subjects were generally mild to moderate in severity, with only a limited representation of subjects with severe COPD.

The Genetic Epidemiology of COPD Study (COPDGene) is a large observational study of over 10,000 current and former smokers, including subjects without airflow obstruction and subjects across the full range of COPD severity [12]. We hypothesized that quantitative analysis of paired inspiratory and expiratory chest CT scans in COPDGene can be used to define indicators of small airway disease that are superior to expiratory CT imaging alone as predictors of lung function and other COPDrelated traits in smokers across a full range of lung function values from normal to very severe COPD.

\section{Methods}

\section{Study subjects}

COPDGene recruited subjects at 21 clinical centers across the U.S [12]. Subjects were non-Hispanic whites or non-Hispanic African Americans ages 45-80, with a smoking history of at least 10 pack-years. Subjects with other diagnosed lung diseases except for asthma were excluded. Subjects underwent a standard study visit which included spirometry before and after albuterol administration, measurement of exercise capacity using a six-minute walk test, questionnaires to assess medical history, respiratory symptoms and medication use, and a 
blood sample. The modified Medical Research Council (MMRC) scale was used to quantify dyspnea [13]. Diseaserelated quality of life was assessed by the St. George's Respiratory Questionnaire (SGRQ) [14]. In COPDGene, COPD was defined and staged according to GOLD criteria [15], despite potential limitations of a fixed $\mathrm{FEV}_{1} / \mathrm{FVC}$ ratio $<0.7$ [16]. Study protocols and questionnaires are available at www.copdgene.org. The COPDGene data release version 16-April-2012 was used for analysis. Subjects provided written informed consent. The study was performed in accordance with the Declaration of Helsinki and was approved by the Institutional Review Boards at Partners Healthcare and all participating centers.

\section{Chest CT scans}

Subjects underwent volumetric CT scans of the chest at full inspiration (standard dose $=200 \mathrm{mAs}$ ) and at end-tidal expiration (low dose $=50 \mathrm{mAs}$ ). Detailed CT protocols have been previously published [12] and are available online at www.copdgene.org. CT scans were subjected to a standard quality control procedure. Subjects with missing or failed inspiratory or expiratory chest CT scans were from this analysis. Computerized image analysis was performed with 3D SLICER software (www.slicer.org) $[17,18]$. Emphysema was quantified by the percent of the lung voxels on inspiratory CT scan with attenuation $<-950$ HU (Insp-950) [19]. The square root of wall area of a hypothetical airway with $10 \mathrm{~mm}$ internal perimeter (SRWA Pi10) [20], measured using VIDA software (www. vidadiagnostics.com), was available in a minority of subjects. Small airway measures on chest CT scan were defined as follows:

1. Expiratory-856 $\left(\right.$ Exp $\left._{-856}\right)$ is defined as the percent of the lung voxels with attenuation $<-856 \mathrm{HU}$ on the expiratory CT images [4]. This has been called "percent gas trapping" in previous COPDGene publications [21-23].

2. Expiratory to Inspiratory Ratio of Mean Lung Attenuation (E/I MLA) is defined as the ratio of mean lung attenuation from the density histograms on expiratory and inspiratory scans $[5-7,9,10]$.

3. Relative Volume Change -856 to $-950\left(R V C_{856-950}\right)$ is defined as the difference between the expiratory and inspiratory values for relative lung volumes, which is the limited lung volume with attenuation between -856 to $950 \mathrm{HU}$ divided by the lung volume without emphysema, according to Matsuoka et al. [8] Relative lung volume on expiratory or inspiratory scan is expressed as:

lung volume with attenuation between -856 and 950HU/

lung volume with attenuation $>-950 \mathrm{HU}$
4. Residuals are the residuals from the linear regression of Expiratory_856 on Inspiratory-950. This statistical approach was used to regress out the effect on emphysema on the Expiratory -856 $_{\text {measure of gas }}$ trapping.

Emphysema was considered absent in subjects with values for Insp-950 $<5 \%$ in ex-smokers and $<4 \%$ in current smokers, to account for the fact that the increased lung density in current smokers results in a decrease in emphysema index [24]. Severe emphysema was defined by Insp-950 $>15 \%$ in ex-smokers and $>14 \%$ in current smokers. Total Lung Capacity (TLC) and Functional Residual Capacity (FRC) were determined from measurement of lung volumes on chest CT scans at full inspiration and relaxed exhalation, respectively [25].

\section{Statistical analysis}

Pearson correlations were used to describe correlations among the small airway measures and between small airway measures and clinical variables. Linear regression models were used to describe the relative contributions of emphysema and small airway disease to lung function and selected clinical parameters. Linear regression models were adjusted for clinically relevant covariates determined a priori. Independent variables, including CT emphysema and small airway parameters, were standardized to mean $=0$ and standard deviation $=1$ in the regression models. The percent of variation explained $\left(R^{2}\right)$ was used to assess the explanatory ability of a regression model. $\mathrm{P}$-value $<0.05$ represents statistical significance. Statistical analyses were conducted using SAS version 9.2 (SAS Institute, Cary, NC).

\section{Reproducibility data}

Thirty-two subjects were inadvertently enrolled twice into COPDGene. Eighteen of those subjects had inspiratory and expiratory chest CT scans performed with the same protocol and passing quality control which were analyzed with 3D SLICER. The eighteen duplicate scans were separated by a median of 224 days (range 38-550). Spearman correlations were used to compare the gas trapping measures in these subjects at the two time points.

\section{Role of the funding source}

The study sponsors had no role in study design; in the collection, analysis, and interpretation of data; in the writing of the report; and in the decision to submit the paper for publication.

\section{Results}

COPDGene enrolled 10,300 subjects, including 108 nonsmoker controls who were excluded from this analysis. Table 1 shows the characteristics of the 8517 current 
Table 1 COPDGene study subjects

\begin{tabular}{|c|c|c|c|}
\hline & All subjects & Severe emphysemał & No emphysema§ \\
\hline N & 8517 & 1188 & 5769 \\
\hline Age & $59.6(9.0)$ & $65.5(7.7)$ & $57.6(8.6)$ \\
\hline \multicolumn{4}{|l|}{ Sex } \\
\hline Male & $4535(53.2 \%)$ & 711 (59.8\%) & $2849(49.4 \%)$ \\
\hline Female & $3982(46.8 \%)$ & $477(40.2 \%)$ & $2920(50.6 \%)$ \\
\hline \multicolumn{4}{|l|}{ Race } \\
\hline African American & $2668(31.3 \%)$ & $190(16.0 \%)$ & $2156(37.4 \%)$ \\
\hline White & $5849(68.7 \%)$ & 998 (84.0\%) & $3613(62.6 \%)$ \\
\hline Current smoking & $4463(52.4 \%)$ & $259(21.8 \%)$ & $3547(61.5 \%)$ \\
\hline Pack-years of smoking & $44.3(24.8)$ & $55.4(27.8)$ & $40.8(22.6)$ \\
\hline GOLD Stage & [54 missing]† & {$[3$ missing] $\dagger$} & [40 missing] $\dagger$ \\
\hline 0 & $3674(43.4 \%)$ & $17(1.4 \%)$ & 3241 (56.6\%) \\
\hline 1 & $668(7.9 \%)$ & 47 (4.0\%) & $414(7.2 \%)$ \\
\hline 2 & $1636(19.3 \%)$ & $263(22.2 \%)$ & $870(15.2 \%)$ \\
\hline 3 & 965 (11.4\%) & $458(38.7 \%)$ & $217(3.8 \%)$ \\
\hline 4 & $502(5.9 \%)$ & $396(33.4 \%)$ & $33(0.6 \%)$ \\
\hline Unclassified* & $1018(12.0 \%)$ & $4(0.3 \%)$ & $954(16.7 \%)$ \\
\hline
\end{tabular}

Non-smokers were excluded. Mean (SD) or $\mathrm{N}(\%)$ is shown.

*Unclassified: $\mathrm{FEV}_{1}<80 \%$ predicted with $\mathrm{FEV}_{1} / \mathrm{FVC}>0.7$.

tGOLD Stage is missing in subjects whose spirometry failed quality control.

‡Severe emphysema defined by Insp-950нu $>15 \%$ ex-smokers, $>14 \%$ current smokers.

$\S$ No emphysema defined by Insp-950HU $<5 \%$ ex-smokers, $<4 \%$ current smokers.

and former smokers with complete inspiratory and expiratory chest CT data. Study subjects encompassed the range of COPD severity across all GOLD stages [15]. Approximately $12 \%$ of subjects were unclassified by GOLD, with reduced $F E V_{1}$, but normal $F E V_{1} / F V C$ ratio; the GOLD-unclassified subjects in COPDGene have been described previously [26]. Surprisingly, $4 \%$ of subjects with severe emphysema on chest CT scan had only mild airflow obstruction on spirometry (GOLD1). Conversely, over $4 \%$ of subjects without emphysema had severe or very severe airflow obstruction (GOLD 3-4).

Among the quantitative CT measures, Exp-856 was most highly correlated with percent emphysema (Table 2, Figure 2). E/I MLA and $\mathrm{RVC}_{856-950}$ were significantly but less strongly correlated, while the residuals are com-

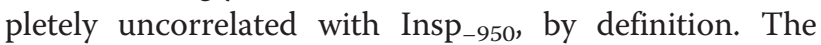
small airway parameters showed varying degrees of correlations among themselves. Correlations between the small airway measures and "medium-sized" airway disease indicated by SRWA Pi10 are weak, except for the correlation with $\mathrm{RVC}_{856-950}$. In 1188 subjects with severe emphysema, E/I MLA was less strongly correlated with percent emphysema than were $\operatorname{Exp}_{-856}$ and $\mathrm{RVC}_{856-950}$ $\left(r=0.40\right.$ for E/I MLA, $r=0.62$ for $\operatorname{Exp}_{-856}, r=0.51$ for $\mathrm{RVC}_{856-950}$; all $\left.\mathrm{p}<0.0001\right)$. E/I MLA was only weakly correlated with Insp-950 in subjects without emphysema, while $\operatorname{Exp}_{-856}$ and $\mathrm{RVC}_{856-950}$ were more highly correlated in this group $(r=0.12$ for E/I MLA, $r=0.50$ for Exp-856, $\mathrm{r}=-0.33$ for $\mathrm{RVC}_{856-950}$; all $\left.\mathrm{p}<0.0001\right)$.

Correlations between the small airway measures, lung function, and other COPD-related traits are shown in Tables 3 and 4. In all subjects, Exp-856 showed the highest correlations with lung function measurements, including $\mathrm{FEV}_{1}, \mathrm{FEV}_{1} / \mathrm{FVC}$ and $\mathrm{FEF}_{25-75}$, a putative small airway disease marker from spirometry. E/I MLA showed a similar correlation as $\operatorname{Exp}_{-856}$ with $\mathrm{FEF}_{25-75}$ in all subjects. $\mathrm{FRC} /$ TLC ratio, a measure of hyperinflation based on chest CT scan-derived lung volumes was most highly correlated with E/I MLA. Exp-856, E/I MLA and $\mathrm{RVC}_{856-950}$ showed similar correlations with SGRQ and MMRC dyspnea score; $\mathrm{RVC}_{856-950}$ was most strongly correlated with 6minute walk distance (6MWD). Residuals showed the weakest correlations with all tested traits.

In subjects with severe emphysema (Table 4), E/I MLA and $\mathrm{RVC}_{856-950}$ were most highly correlated with all tested traits, except for $\mathrm{FEV}_{1} / \mathrm{FVC}$ which showed a slightly higher correlation with $\operatorname{Exp}_{-856}$. Again, residuals showed the poorest correlations with lung function, 6-minute walk distance and symptoms. In subjects without significant emphysema (Additional file 1: Table S1), $\mathrm{RVC}_{856-950}$ or E/I MLA generally showed the strongest correlations. E/I MLA was most highly correlated with $\mathrm{FEV}_{1} / \mathrm{FVC}, \mathrm{FEF}_{25-75}$ and FRC/TLC ratio. Residuals generally showed the weakest correlations with all tested outcomes. 
Table 2 Correlations between quantitative CT measures in COPDGene subjects

\begin{tabular}{|c|c|c|c|c|c|c|c|c|}
\hline & \multirow[b]{2}{*}{$\mathbf{N}$} & \multirow[b]{2}{*}{ Mean(SD) } & \multicolumn{6}{|c|}{ Correlations } \\
\hline & & & $\begin{array}{l}\text { \%emph } \\
\text { Insp -950 }\end{array}$ & $\operatorname{Exp}_{-856}$ & $\begin{array}{l}\text { E/I mean } \\
\text { lung atten. }\end{array}$ & RVC $_{856-950}$ & Residuals & SWRA Pi10 \\
\hline \%emphysema Insp -950 & 8517 & $6.2(9.7)$ & -- & & & & & \\
\hline \% Exp -856 & 8517 & $21.9(19.9)$ & $0.83+$ & -- & & & & \\
\hline E/I mean lung attenuation & 8517 & $0.87(0.07)$ & $0.51+$ & $0.80+$ & -- & & & \\
\hline RVC $_{856-950}$ & 8517 & $-0.37(0.18)$ & $0.37 \dagger$ & $0.48+$ & $0.58+$ & -- & & \\
\hline Residuals & 8517 & $0(11.2)$ & 0 & $0.56+$ & $0.67 \dagger$ & $0.32 \dagger$ & -- & \\
\hline SRWA Pi10 (mm) & 2867 & $3.75(0.12)$ & $0.06^{*}$ & $0.13 \dagger$ & $0.23 \dagger$ & $0.46+$ & $0.15+$ & -- \\
\hline
\end{tabular}

Pearson correlation coefficients are shown.

${ }^{*} \mathrm{p}<0.01$.

$\mathrm{tp}<0.0001$.

Table 5 shows the joint effects of emphysema (Insp-950) and each of three small airway measures (Exp-856, E/I MLA, and $\mathrm{RVC}_{856-950}$ ) on the COPD-related traits $\mathrm{FEV}_{1}$, $\mathrm{FEV}_{1} / \mathrm{FVC}, \mathrm{FEF}_{25-75}$, 6-minute walk distance and SGRQ. Residuals were not used in the regression analysis due to consistently weak correlations in the earlier analyses. Emphysema and gas trapping variables were standardized, so the regression coefficients reflect the effect of a one standard deviation change in each $\mathrm{CT}$ variable. Based on percent variation explained $\left(R^{2}\right)$, all three small airway measures were equally predictive of $\mathrm{FEV}_{1}$. The effects of emphysema and gas trapping on $\mathrm{FEV}_{1}$ were equivalent when either $\mathrm{E} / \mathrm{I}$ MLA or $\mathrm{RVC}_{856-950}$ were used as the gas trapping measure, whereas the gas trapping variable exerted more than three times the effect of emphysema $(-0.45 \mathrm{~L}$ vs. $-0.11 \mathrm{~L})$ in the model using Exp-856. Models including either $\operatorname{Exp}_{-856}$ or E/I MLA explained more of the variation in $\mathrm{FEV}_{1} / \mathrm{FVC}$ and in $\mathrm{FEF}_{25-75}$ than the model
A

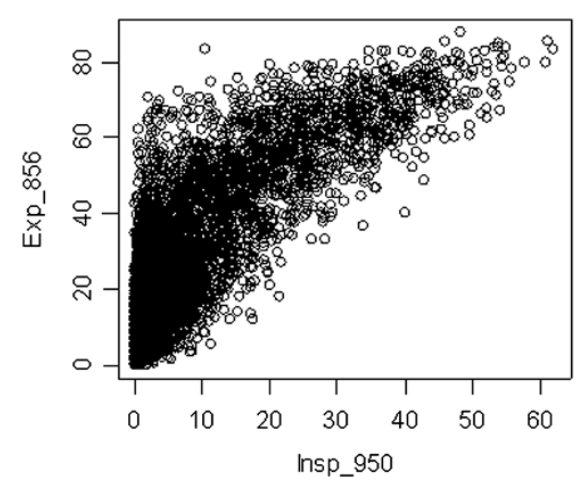

C

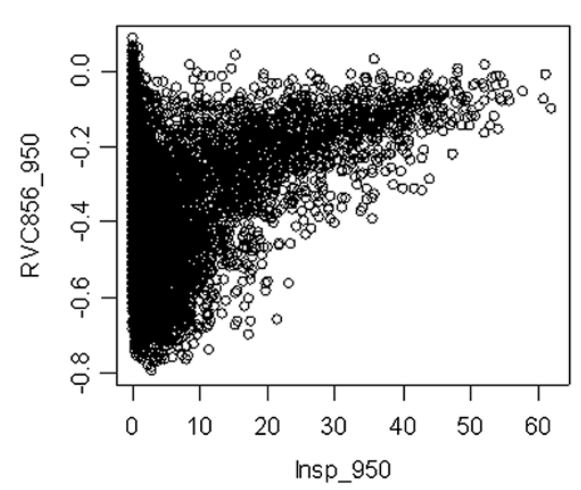

B Exp/nsp Mean Lung Attenuation

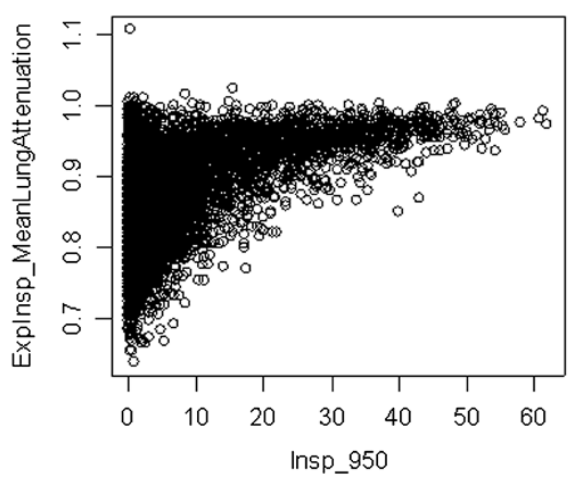

D

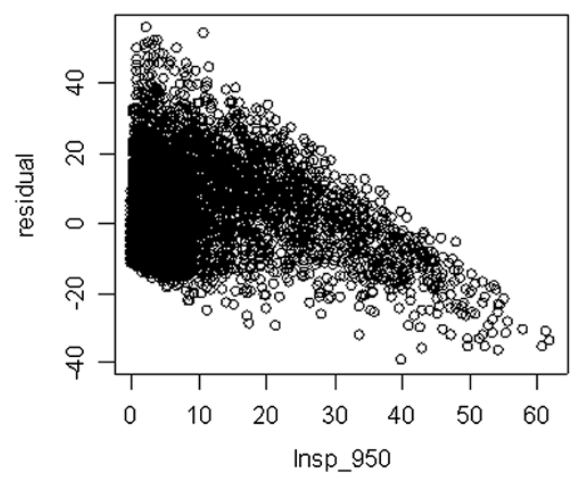

Figure 2 Scatterplots of four gas trapping measurements vs. percent emphysema (see Methods for definitions). 
Table 3 Correlations between gas trapping measures and quantitative outcomes in all subjects

\begin{tabular}{|c|c|c|c|c|c|c|}
\hline & \multirow[b]{2}{*}{$\mathbf{N}$} & \multirow[b]{2}{*}{ Mean (SD) } & \multicolumn{4}{|c|}{ Correlations } \\
\hline & & & $\operatorname{Exp}_{-856}$ & E/I MLA & $\mathrm{RVC}_{856-950}$ & Residual \\
\hline $\mathrm{FEV}_{1} \%$ predicted & 8463 & $76.6(25.5)$ & $-0.69^{*}$ & $-0.60^{*}$ & $-0.54^{*}$ & $-0.33^{*}$ \\
\hline FVC \% predicted & 8463 & $87.2(18.2)$ & $-0.33^{*}$ & $-0.32^{*}$ & $-0.44^{*}$ & $-0.18^{*}$ \\
\hline $\mathrm{FEV}_{1} / \mathrm{FVC}$ & 8463 & $0.67(0.16)$ & $-0.82^{*}$ & $-0.67^{*}$ & $-0.41^{*}$ & $-0.37^{*}$ \\
\hline $\mathrm{FEF}_{25-75}$ & 8463 & $1.75(1.25)$ & $-0.60^{*}$ & $-0.59^{*}$ & $-0.38^{*}$ & $-0.36^{*}$ \\
\hline FRC/TLC ratio & 8517 & $0.58(0.13)$ & $0.65^{*}$ & $0.89^{*}$ & $0.76^{*}$ & $0.65^{*}$ \\
\hline 6MWD & 8407 & $1363(397)$ & $-0.32^{*}$ & $-0.34^{*}$ & $-0.46^{*}$ & $-0.18^{*}$ \\
\hline Exacerbation frequency & 8517 & $0.4(0.9)$ & $0.26^{*}$ & $0.22^{*}$ & $0.19^{*}$ & $0.12^{*}$ \\
\hline SGRQ total & 8517 & $27.0(22.8)$ & $0.39^{*}$ & $0.36^{*}$ & $0.43^{*}$ & $0.20^{*}$ \\
\hline MMRC dyspnea & 8506 & $1.3(1.4)$ & $0.36^{*}$ & $0.32^{*}$ & $0.42^{*}$ & $0.15^{*}$ \\
\hline
\end{tabular}

Pearson correlation coefficients are shown.

${ }^{*} p<0.0001$.

including $\mathrm{RVC}_{856-950}$. The three gas trapping variables were similar in models predicting 6MWD and SGRQ score in all subjects.

In subjects with severe emphysema (Table 6), models with $\mathrm{E} / \mathrm{I}$ MLA or $\mathrm{RVC}_{856-950}$ were better predictors of $\mathrm{FEV}_{1}$ than was Exp ${ }_{-856}$. Only the model using E/I MLA captured significant effects from both emphysema and gas trapping variables. All three small airway measures yielded similarly predictive models for $\mathrm{FEV}_{1} / \mathrm{FVC}, \mathrm{FEF}_{25-75}$, 6MWD, and SGRQ. In the analysis of 6MWD, use of Exp $_{-856}$ led to a significant positive effect of gas trapping, meaning an increase in the gas trapping variable corresponded to an increase in 6MWD among severe emphysema subjects. The 6MWD models with E/I MLA or $\mathrm{RVC}_{856-950}$ captured significant effects of emphysema only, with an expected direction of effect, namely reduction in 6MWD. Both E/I MLA and $\mathrm{RVC}_{856-950}$ identified statistically significant effects of gas trapping on SGRQ score in subjects with severe emphysema.
In subjects without significant emphysema, models including each of the small airway measures explained similar fractions of the variation in the COPD-related traits, with the exception of $\mathrm{RVC}_{856-950}$ predicting $\mathrm{FEV}_{1} / \mathrm{FVC}$ (Additional file 2: Table S2). In these subjects, quantitative emphysema measurements were not significantly associated with $\mathrm{FEV}_{1}, \mathrm{FEV}_{1} / \mathrm{FVC}$ or $6 \mathrm{MWD}$ when E/I MLA was used as the gas trapping indicator.

In the eighteen subjects with repeat quantitative CT data, the gas trapping measures from the two time points were significantly correlated within each subject: $\operatorname{Exp}_{-856} \rho=0.79, \mathrm{p}<0.0001$; E/I MLA $\rho=0.67, \mathrm{p}=0.002$; $\mathrm{RVC}_{856-950} \rho=0.54, \mathrm{p}=0.02$.

\section{Discussion}

In the largest cohort of smokers with quantitative chest CT data published to date, we evaluated four variables to measure gas trapping as a surrogate for small airway disease, since the airways of interest are below the

Table 4 Correlations between gas trapping measures and quantitative outcomes in subjects with severe emphysema (Insp-950нU > 15\% ex-smokers, Insp_-950HU > 14\% current smokers)

\begin{tabular}{|c|c|c|c|c|c|c|}
\hline & \multirow[b]{2}{*}{$\mathbf{N}$} & \multirow[b]{2}{*}{ Mean (SD) } & \multicolumn{4}{|c|}{ Correlations } \\
\hline & & & $\operatorname{Exp}_{-856}$ & E/I MLA & $\mathrm{RVC}_{856-950}$ & Residual \\
\hline $\mathrm{FEV}_{1} \%$ predicted & 1185 & $41.2(19.9)$ & $-0.69 \neq$ & $-0.73 \neq$ & $-0.73 \neq$ & $-0.16 \neq$ \\
\hline FVC \% predicted & 1185 & $75.7(21.1)$ & $-0.49 \neq$ & $-0.56 \neq$ & $-0.57 \ddagger$ & $-0.17 \ddagger$ \\
\hline $\mathrm{FEV}_{1} / \mathrm{FVC}$ & 1185 & $0.40(0.12)$ & $-0.66 \neq$ & $-0.62 \ddagger$ & $-0.62 \ddagger$ & $-0.08^{*}$ \\
\hline $\mathrm{FEF}_{25-75}$ & 1185 & $0.42(0.38)$ & $-0.56 \neq$ & $-0.61 \neq$ & $-0.61 \neq$ & $-0.18 \neq$ \\
\hline FRC/TLC ratio & 1188 & $0.69(0.12)$ & $0.80^{*}$ & $0.93^{*}$ & $0.87^{*}$ & $0.44^{*}$ \\
\hline $6 \mathrm{MWD}$ & 1135 & $1116(404)$ & $-0.31 \neq$ & $-0.40 \neq$ & $-0.43 \neq$ & $-0.01^{\mathrm{NS}}$ \\
\hline Exacerbation frequency & 1188 & $0.8(1.2)$ & $0.10 \dagger$ & $0.12 \neq$ & $0.13 \neq$ & $-0.02^{\mathrm{NS}}$ \\
\hline SGRQ total & 1188 & 44.9 (19.9) & $0.32 \neq$ & $0.41 \neq$ & $0.43 \neq$ & $0.09^{*}$ \\
\hline MMRC dyspnea & 1183 & $2.5(1.3)$ & $0.34 \ddagger$ & $0.38 \neq$ & $0.42 \ddagger$ & $0.01^{\mathrm{NS}}$ \\
\hline
\end{tabular}

Pearson correlation coefficients are shown.

${ }^{*} \mathrm{p}<0.01$.

$t \mathrm{p}<0.001$.

$\neq \mathrm{p}<0.0001$.

NS $=$ not significant $(p>0.05)$. 
Table $\mathbf{5}$ Regression models for lung function, exercise capacity and symptoms in all subjects

\begin{tabular}{|c|c|c|c|c|c|c|}
\hline \multicolumn{7}{|c|}{ A. Linear regression for $\mathrm{FEV}_{1}(\mathrm{~L})$} \\
\hline & \multicolumn{2}{|c|}{ Exp-856 $_{-85}$} & \multicolumn{2}{|c|}{ E/I MLA } & \multicolumn{2}{|c|}{$\mathrm{RVC}_{856-950}$} \\
\hline Independent variables & $\beta^{*}$ & $p$-value & $\beta^{*}$ & $\mathrm{p}$-value & $\beta^{*}$ & $p$-value \\
\hline \% emphysema (Insp_950) & -0.11 & $<0.0001$ & -0.31 & $<0.0001$ & -0.29 & $<0.0001$ \\
\hline Gas Trapping variablet & -0.45 & $<0.0001$ & -0.30 & $<0.0001$ & -0.30 & $<0.0001$ \\
\hline \multicolumn{7}{|l|}{ Model fit statistics } \\
\hline$R^{2}$ & \multicolumn{2}{|c|}{0.67} & \multicolumn{2}{|c|}{0.68} & \multicolumn{2}{|c|}{0.68} \\
\hline \multicolumn{7}{|c|}{ B. Linear regression for $\mathrm{FEV}_{1} / \mathrm{FVC}$} \\
\hline & \multicolumn{2}{|c|}{$\operatorname{Exp}_{-856}$} & \multicolumn{2}{|c|}{$\mathrm{E} / \mathrm{I} \mathrm{MLA}$} & \multicolumn{2}{|c|}{$\mathrm{RVC}_{856-950}$} \\
\hline Independent variables & $\beta^{*}$ & $p$-value & $\beta^{*}$ & $p$-value & $\beta^{*}$ & $p$-value \\
\hline \% emphysema (Insp_950) & -0.03 & $<0.0001$ & -0.09 & $<0.0001$ & -0.10 & $<0.0001$ \\
\hline Gas Trapping variablet & -0.10 & $<0.0001$ & -0.06 & $<0.0001$ & -0.03 & $<0.0001$ \\
\hline \multicolumn{7}{|l|}{ Model fit statistics } \\
\hline$\overline{R^{2}}$ & \multicolumn{2}{|c|}{0.73} & \multicolumn{2}{|c|}{0.70} & \multicolumn{2}{|c|}{0.64} \\
\hline \multicolumn{7}{|c|}{ C. Linear regression for $\mathrm{FEF}_{25-75}$} \\
\hline & \multicolumn{2}{|c|}{ Exp-856 $_{-85}$} & \multicolumn{2}{|c|}{$\mathrm{E} / \mathrm{I} \mathrm{MLA}$} & \multicolumn{2}{|c|}{$\mathrm{RVC}_{856-950}$} \\
\hline Independent variables & $\beta^{*}$ & $p$-value & $\beta^{*}$ & $p$-value & $\beta^{*}$ & $p$-value \\
\hline \% emphysema (Insp_950) & 0.0002 & 0.99 & -0.29 & $<0.0001$ & -0.38 & $<0.0001$ \\
\hline Gas Trapping variablet & -0.68 & $<0.0001$ & -0.51 & $<0.0001$ & -0.24 & $<0.0001$ \\
\hline \multicolumn{7}{|l|}{ Model fit statistics } \\
\hline$R_{2}$ & \multicolumn{2}{|c|}{0.50} & \multicolumn{2}{|c|}{0.52} & \multicolumn{2}{|c|}{0.45} \\
\hline \multicolumn{7}{|c|}{ D. Linear regression for 6-minute walk distance (ft). } \\
\hline & \multicolumn{2}{|c|}{ Exp-856 $_{-85}$} & \multicolumn{2}{|c|}{$\mathrm{E} / \mathrm{MLA}$} & \multicolumn{2}{|c|}{$\mathrm{RVC}_{856-950}$} \\
\hline Independent variables & $\beta^{*}$ & p-value & $\beta^{*}$ & $\mathrm{p}$-value & $\beta^{*}$ & $p$-value \\
\hline \% emphysema (Insp_-950) & -47.8 & $<0.0001$ & -46.3 & $<0.0001$ & -37.3 & $<0.0001$ \\
\hline Gas Trapping variablet & -3.7 & 0.6 & -22.0 & $<0.0001$ & -51.8 & $<0.0001$ \\
\hline Model fit statistics & & & & & & \\
\hline $\mathrm{R}^{2}$ & & & & & & \\
\hline E. Linear regression for SG & ore. & & & & & \\
\hline & & & & & & \\
\hline Independent variables & $\beta^{*}$ & $p$-value & $\beta^{*}$ & $p$-value & $\beta^{*}$ & $p$-value \\
\hline \% emphysema (Insp_950) & 1.3 & 0.0004 & 2.8 & $<0.0001$ & 2.7 & $<0.0001$ \\
\hline Gas Trapping variablet & 3.2 & $<0.0001$ & 1.9 & $<0.0001$ & 1.7 & $<0.0001$ \\
\hline Model fit statistics & & & & & & \\
\hline$\overline{R^{2}}$ & & & & & & \\
\hline
\end{tabular}

All models are adjusted for age, sex, race, clinical center, current smoking status, pack-years of smoking, height, weight, Siemens 64 scanner. Models for 6-minute walk distance (D) and SGRQ score (E) were additionally adjusted for FEV1\% predicted.

*Independent variables standardized to mean $=0$ and $S D=1 . \beta=$ change in dependent variable, e.g. $F E V_{1}(L)$, for each SD change in independent variable.

tEither $\operatorname{Exp}_{-856}$, E/I mean lung attenuation ratio, or $\mathrm{RVC}_{856-950}$.

resolution of $\mathrm{CT}$ imaging. Three of the variables were defined in an effort to separate gas trapping due to small airway disease from gas trapping due to emphysema. The residuals from regression of expiratory air trapping on emphysema showed consistently poor correlations and were not tested in multivariable models. In general, the other three measures - percent of lung with attenuation $<-856 \mathrm{HU}$ on expiratory chest CT scan, the expiratory to inspiratory ratio of mean lung attenuation, and the relative volume change ${ }_{856-950}$ - were similarly predictive of lung function, exercise capacity and quality of life when all subjects were considered together (Table 5). However, in subjects with severe emphysema, the two measures that utilized paired inspiratory and expiratory CT scans - E/I MLA and $\mathrm{RVC}_{856-950}$ - yielded more predictive associations (Table 6). The paired measures performed adequately in subjects without significant emphysema as well (Additional file 2: Table S2). The variables had reasonable reproducibility in a small subset of subjects with duplicate chest CT scans, although repeat 
Table 6 Regression models for lung function, exercise capacity and symptoms in subjects with severe emphysema

\begin{tabular}{|c|c|c|c|c|c|c|}
\hline \multicolumn{7}{|c|}{ A. Linear regression for $\mathrm{FEV}_{1}(\mathrm{~L})$} \\
\hline & \multicolumn{2}{|c|}{$\operatorname{Exp}_{-856}$} & \multicolumn{2}{|c|}{ E/I MLA } & \multicolumn{2}{|c|}{$\mathrm{RVC}_{856-950}$} \\
\hline Independent variables & $\beta^{*}$ & p-value & $\beta^{*}$ & p-value & $\beta^{*}$ & $p$-value \\
\hline \% emphysema (Insp_950) & 0.01 & 0.5 & -0.08 & $<0.0001$ & -0.01 & 0.3 \\
\hline Gas Trapping variablet & -0.46 & $<0.0001$ & -0.43 & $<0.0001$ & -0.46 & $<0.0001$ \\
\hline \multicolumn{7}{|l|}{ Model fit statistics } \\
\hline$R^{2}$ & \multicolumn{2}{|c|}{0.63} & \multicolumn{2}{|c|}{0.68} & \multicolumn{2}{|c|}{0.67} \\
\hline \multicolumn{7}{|c|}{ B. Linear regression for $\mathrm{FEV}_{1} / \mathrm{FVC}$} \\
\hline & \multicolumn{2}{|c|}{$\operatorname{Exp}_{-856}$} & \multicolumn{2}{|c|}{$E / / M L A$} & \multicolumn{2}{|c|}{$\mathrm{RVC}_{856-950}$} \\
\hline Independent variables & $\beta^{*}$ & $p$-value & $\beta^{*}$ & p-value & $\beta^{*}$ & $p$-value \\
\hline \% emphysema (Insp_950) & -0.01 & 0.004 & -0.03 & $<0.0001$ & -0.02 & $<0.0001$ \\
\hline Gas Trapping variablet & -0.08 & $<0.0001$ & -0.07 & $<0.0001$ & -0.07 & $<0.0001$ \\
\hline \multicolumn{7}{|l|}{ Model fit statistics } \\
\hline$\overline{R^{2}}$ & \multicolumn{2}{|c|}{0.52} & \multicolumn{2}{|c|}{0.52} & \multicolumn{2}{|c|}{0.49} \\
\hline \multicolumn{7}{|c|}{ C. Linear regression for $\mathrm{FEF}_{25-75}$} \\
\hline & \multicolumn{2}{|c|}{$\operatorname{Exp}_{-856}$} & \multicolumn{2}{|c|}{$E / / M L A$} & \multicolumn{2}{|c|}{$\mathrm{RVC}_{856-950}$} \\
\hline Independent variables & $\beta^{*}$ & $p$-value & $\beta^{*}$ & p-value & $\beta^{*}$ & $p$-value \\
\hline \% emphysema (Insp_950) & 0.01 & 0.3 & -0.04 & 0.0001 & -0.004 & 0.7 \\
\hline Gas Trapping variablet & -0.24 & $<0.0001$ & -0.23 & $<0.0001$ & -0.24 & $<0.0001$ \\
\hline \multicolumn{7}{|l|}{ Model fit statistics } \\
\hline $\mathrm{R}^{2}$ & \multicolumn{2}{|c|}{0.46} & \multicolumn{2}{|c|}{0.50} & \multicolumn{2}{|c|}{0.49} \\
\hline \multicolumn{7}{|c|}{ D. Linear regression for 6-minute walk distance (ft). } \\
\hline & \multicolumn{2}{|c|}{ Exp-856 $_{-85}$} & \multicolumn{2}{|c|}{ E/I MLA } & \multicolumn{2}{|c|}{$\mathrm{RVC}_{856-950}$} \\
\hline Independent variables & $\beta^{*}$ & p-value & $\beta^{*}$ & p-value & $\beta^{*}$ & $p$-value \\
\hline \% emphysema (Insp_-950) & -66.6 & $<0.0001$ & -51.7 & $<0.0001$ & -46.6 & 0.0002 \\
\hline Gas Trapping variablet & 41.4 & 0.01 & -3.4 & 0.8 & -22.4 & 0.2 \\
\hline Model fit statistics & & & & & & \\
\hline$R^{2}$ & & & & & & \\
\hline E. Linear regression for SG & ore. & & & & & \\
\hline & & & & & & \\
\hline Independent variables & $\beta^{*}$ & $p$-value & $\beta^{*}$ & $p$-value & $\beta^{*}$ & $p$-value \\
\hline \% emphysema (Insp_950) & 0.9 & 0.2 & 0.9 & 0.1 & 0.1 & 0.8 \\
\hline Gas Trapping variablet & 1.1 & 0.2 & 3.0 & 0.0001 & 4.4 & $<0.0001$ \\
\hline Model fit statistics & & & & & & \\
\hline$\overline{R^{2}}$ & & & & & & \\
\hline
\end{tabular}

All models are adjusted for age, sex, race, clinical center, current smoking status, pack-years of smoking, height, weight, Siemens 64 scanner. Models for 6-minute walk distance (D) and SGRQ score (E) were additionally adjusted for FEV1\% predicted.

*Independent variables standardized to mean $=0$ and $S D=1 . \beta=$ change in dependent variable, e.g. $F E V_{1}(L)$, for each SD change in independent variable.

tEither $\operatorname{Exp}_{-856}$, E/I mean lung attenuation ratio, or $\mathrm{RVC}_{856-950}$.

correlations were stronger Exp_856 than for E/I MLA or $\mathrm{RVC}_{856-950}$, since the latter two measures incorporate variability from both inspiratory and expiratory acquisitions.

Assessment of low attenuation areas on expiratory chest CT scans was initially described as a marker for gas trapping in studies of asthma [27]. The Severe Asthma Research Program proposed the threshold of $856 \mathrm{HU}$ [4]. As opposed to asthma, in COPD both emphysema and gas trapping from small airway disease may lead to increased values for $\operatorname{Exp}_{-856}$.
Several groups have examined paired inspiratory and expiratory CT scan measures of gas trapping in COPD. The majority of papers have used the expiratory to inspiratory ratio of mean lung attenuation, which has also been referred to as the ratio of mean lung density [5-7,10]. Matsuoka and colleagues defined $\mathrm{RVC}_{850-950}$ [8], similar to $\mathrm{RVC}_{856-950}$ in the current analysis. These previous studies have found good correlations between pulmonary function measures and gas trapping. However, the sample sizes in the published papers have 
generally been small and most of the papers have only considered a single gas trapping metric. Mets and colleagues compared several different gas trapping measures in 248 subjects [9]. Similar to our analysis, they found that the two paired measures - E/I MLA and $\mathrm{RVC}_{860-950}$ in their study - had the strongest correlations with lung function. We confirmed these findings in a much larger cohort, and found parallel correlations with important clinical outcomes including exercise capacity and quality of life. Most of the previous papers performed expiratory $\mathrm{CT}$ scans at full expiration (RV), whereas COPDGene scans were performed at end-tidal expiration, corresponding to FRC.

A recently published Dutch lung cancer screening study acquired low-dose inspiratory and end-expiratory chest CT scans in 1140 male smokers at a single center [11]. A multivariable model which included both CT emphysema (Insp_-950) and E/I MLA as a marker of gas trapping was highly accurate in predicting COPD. Although 437 (38\%) subjects had COPD based on spirometry, only 25 subjects had severe COPD (GOLD 3) and none had very severe COPD (GOLD 4).

The large number of subjects with quantitative analysis of inspiratory and expiratory chest CT scans is one of the strengths of the COPDGene study. The sample size in COPDGene is nearly ten times as large as the Dutch cancer screening study [11]. COPDGene included smokers with normal lung function and with the full range of lung function impairment, in contrast to previous papers. Including subjects with severe and very severe COPD (GOLD 3-4) allowed for the analysis in subjects with severe emphysema, though emphysema severity did not completely correlate with GOLD stage. The extensive clinical characterization in COPDGene allowed us to select a range of COPD-related traits including spirometry, exercise capacity and disease related quality of life. Subjects in COPDGene were enrolled at multiple clinical centers and underwent $\mathrm{CT}$ scans on different scanner models, yet we were able to find robust associations which were applicable across the multi-center study.

Ideally, one would test the CT measures of small airway disease against physiologic measures that have been traditionally used to measure small airway disease, including the RV/TLC ratio. However, lung volumes were not measured by pulmonary function testing in COPDGene, but were assessed on chest CT scans. E/I MLA showed the strongest correlation with the CTderived FRC/TLC ratio, a marker of hyperinflation. Study subjects were given standard instructions for breath-holds at full inspiration (TLC) and end-tidal expiration (FRC), but the chest CT scans did not use spirometric gating to ensure compliance. The $\mathrm{CT}$ scanning protocol in COPDGene more accurately reflects clinical practice and still provides important information in the research setting. We did find significant correlations with $\mathrm{FEF}_{25-75}$, a putative small airway disease measurement on spirometry. Measurement of carbon monoxide diffusing capacity (DLCO) can be used as an indicator of emphysema on pulmonary function testing; however DLCO was not measured in the COPDGene Study. The CT measures may complement standard lung function testing in the evaluation of COPD patients.

Besides histology, direct visualization of the small airways would be the optimal metric for small airway disease in smokers. This can be performed ex vivo using microCT [28], but is not feasible in living patients. There is substantial literature using measurements of airway disease in larger airways, such as SRWA Pi10 [20]. Papers from COPDGene have found correlations between segmental and subsegmental airway wall measures and clinical traits including exacerbations [29], chronic bronchitis [30], pulmonary function [31] and quality of life [32]. These approaches rely on the assumption that similar pathological processes are occurring in the small airways and the more proximal airways. At present, the choice of the best airway wall measurement is not clear, and any such measure on the larger airways is primarily a surrogate for small airway disease. Pairing standard inspiratory chest CT scans with low dose expiratory scans can provide an alternative marker for airflow obstruction in the small airways in smokers, yet most large COPD studies do not acquire expiratory CT scans $[33,34]$.

\section{Conclusions}

We have shown that two previously-described gas trapping measures based on paired inspiratory and expiratory chest CT scans (E/I MLA and $\mathrm{RVC}_{856-950}$ ) may serve as markers of small airway disease in smokers, including subjects with severe and very severe COPD. Although we cannot claim that one measure is superior to the other, the expiratory to inspiratory ratio of mean lung attenuation may be more straightforward than $\mathrm{RVC}_{856-950}$, and has more support in the published COPD literature. For clinical applicability, it will be important to define thresholds for these gas trapping parameters that delineate normal from small airway disease; a large sample of never smokers with normal lung function is necessary for this effort. Additionally, thresholds to define airwaypredominant vs. emphysema-predominant COPD subtypes are also desirable. The current data do not allow for assessment of changes in these measures with treatment, an important area for future investigation. Large studies of smokers will have to include expiratory CT scans to further these efforts. In COPDGene and future studies, these gas trapping variables can be used in genetic analyses, to better understand the pathobiology of COPD subtypes. 


\section{Additional files}

Additional file 1: Table S1. Correlations between gas trapping measures and quantitative outcomes in subjects without emphysema (Insp-950 $<5 \%$ ex-smokers, $<4 \%$ current smokers).

Additional file 2: Table S2. Regression models for lung function, exercise capacity and symptoms in subjects without emphysema.

\section{Competing interests}

Dr. Hersh has received lecture fees from Novartis. Dr. Han has served as a consultant for Boehringer Ingelheim, Pfizer, GSK, Medimmune, Novartis, Grifols Therapeutics, and United Biosource Corporation. She has received royalties from UpToDate. She has developed educational presentations for National Association for Continuing Education and WebMD. Dr. Lynch has received grant support from Siemens and Centocor. He has served as a consultant for Perceptive Imaging, Intermune and Gilead.

Dr. Make has served on advisory boards for Forest, AstraZeneca, Novartis, Coviden, Breathe, Merck, Sunovion, Boehringer Ingelheim, MedImmune, Ikaria, and Novartis. He has served as a consultant for Astellas. He reports grant support from AstraZeneca, GlaxoSmithKline, NABI, Boehringer Ingelheim, Sunovion, and Forest. He has received lecture fees from GlaxoSmithKline, Boehringer Ingelheim, Pfizer, and Forest. He has received royalties from UpToDate. Dr. Newell has served as a consultant for VIDA Diagnostics. Dr. Sciurba has participated in consulting for GSK, AstraZeneca and Pfizer and has received research grant funding from the NIH, GSK, Bl, Pfizer, Forest and Actelion. Dr. Silverman has served as a consultant for GlaxoSmithKline, AstraZeneca, and Merck. He has received grant support from GlaxoSmithKline. He has received lecture fees from GlaxoSmithKline and AstraZeneca. Drs. Washko, San José Estépar, Lutz, Friedman, Hokanson, Judy, Marchetti and Crapo do not report any competing interests.

\section{Authors' contributions}

Study concept and design: CPH, GRW, PJF, MKH, JEH, PFJ, DAL, BJM, NM, JDN, FCS, JDC, EKS. Data collection: CPH, GRW, RSJE, PJF, MKH, JEH, PFJ, DAL, BJM, NM, JDN, FCS, JDC, EKS. Data analysis: CPH, RSJE, SL. Manuscript drafting: $\mathrm{CPH}$. Manuscript revision and final approval: All authors.

\section{Acknowledgements}

Supported by U.S. National Institutes of Health grants R01HL094635 (CPH), R01NR013377 (CPH), U01HL089856 (EKS), U01HL089897 (JDC). COPDGene is also supported by the COPD Foundation through contributions made to an Industry Advisory Board comprised of AstraZeneca, Pfizer, Novartis, Boehringer-Ingelheim, and Sunovion. The sponsors had no role in data analysis or manuscript writing, editing or submission.

Members of the COPDGene ${ }^{\circledR}$ study group:

Ann Arbor VA: Jeffrey Curtis, MD (PI), Ella Kazerooni, MD (RAD) Baylor College of Medicine, Houston, TX: Nicola Hanania, MD, MS (PI), Philip Alapat, MD, Venkata Bandi, MD, Kalpalatha Guntupalli, MD, Elizabeth Guy, MD, Antara Mallampalli, MD, Charles Trinh, MD (RAD), Mustafa Atik, MD Brigham and Women's Hospital, Boston, MA: Dawn DeMeo, MD, MPH (Co-PI), Craig Hersh, MD, MPH (Co-PI), George Washko, MD, Francine Jacobson, MD, MPH (RAD)

Columbia University, New York, NY: R. Graham Barr, MD, DrPH (PI), Byron Thomashow, MD, John Austin, MD (RAD)

Duke University Medical Center, Durham, NC: Neil Maclntyre, Jr., MD (PI), Lacey Washington, MD (RAD), H Page McAdams, MD (RAD)

Fallon Clinic, Worcester, MA: Richard Rosiello, MD (PI), Timothy Bresnahan, MD (RAD) Health Partners Research Foundation, Minneapolis, MN: Charlene McEvoy, MD, $\mathrm{MPH}(\mathrm{PI})$, Joseph Tashjian, MD (RAD)

Johns Hopkins University, Baltimore, MD: Robert Wise, MD (PI), Nadia Hansel, MD, MPH, Robert Brown, MD (RAD), Gregory Diette, MD

Los Angeles Biomedical Research Institute at Harbor UCLA Medical Center, Los Angeles, CA: Richard Casaburi, MD, PhD (PI), Janos Porszasz, MD, PhD, Hans Fischer, MD, PhD (RAD), Matt Budoff, MD

Michael E. DeBakey VAMC, Houston, TX: Amir Sharafkhaneh, MD (PI), Charles Trinh, MD (RAD), Hirani Kamal, MD, Roham Darvishi, MD Minneapolis VA: Dennis Niewoehner, MD (PI), Tadashi Allen, MD (RAD), Quentin Anderson, MD (RAD), Kathryn Rice, MD Morehouse School of Medicine, Atlanta, GA: Marilyn Foreman, MD, MS (PI), Gloria Westney, MD, MS, Eugene Berkowitz, MD, PhD (RAD)
National Jewish Health, Denver, CO: Russell Bowler, MD, PhD (PI), David Lynch, MB (RAD), Joyce Schroeder, MD (RAD)

Temple University, Philadelphia, PA: Gerard Criner, MD (PI), Victor Kim, MD Nathaniel Marchetti, DO, Aditi Satti, MD, A. James Mamary, MD, Robert Steiner, MD (RAD), Chandra Dass, MD (RAD)

University of Alabama, Birmingham, AL: Mark Dransfield, MD (PI), William Bailey, MD, Hrudaya Nath, MD (RAD)

University of California, San Diego, CA: Joe Ramsdell, MD (PI), Paul Friedman, $\mathrm{MD}$ (RAD)

University of lowa, lowa City, IA: Alejandro Comellas, MD (PI), Brad Thompson, MD (RAD), John Newell, Jr., MD (RAD)

University of Michigan, Ann Arbor, MI: Fernando Martinez, MD (PI), MeiLan Han, MD, Ella Kazerooni, MD (RAD)

University of Minnesota, Minneapolis, MN: Christine Wendt, MD (PI), Tadashi Allen, MD (RAD)

University of Pittsburgh, Pittsburgh, PA: Frank Sciurba, MD (PI), Joel Weissfeld, MD, MPH, Carl Fuhrman, MD (RAD), Jessica Bon, MD

University of Texas Health Science Center at San Antonio, San Antonio, TX: Antonio Anzueto, MD (PI), Sandra Adams, MD, Carlos Orozco, MD, Mario Ruiz, MD (RAD)

Administrative Core: James Crapo, MD (PI), Edwin Silverman, MD, PhD (PI), Barry Make, MD, Elizabeth Regan, MD, Sarah Moyle, MS, Douglas Stinson Genetic Analysis Core: Terri Beaty, PhD, Nan Laird, PhD, Christoph Lange, PhD, Michael Cho, MD, Stephanie Santorico, PhD, John Hokanson, MPH, PhD, Dawn DeMeo, MD, MPH, Nadia Hansel, MD, MPH, Craig Hersh, MD, MPH, Sharon Lutz, PhD, Merry-Lynn McDonald, PhD, Jacqueline Hetmanski, MS, Tanda Murray Imaging Core: David Lynch, MB, Joyce Schroeder, MD, John Newell, Jr., MD, John Reilly, MD, Harvey Coxson, PhD, Philip Judy, PhD, Eric Hoffman, PhD, George Washko, MD, Raul San Jose Estepar, PhD, Edwin JR van Beek, MD, PhD, James Ross, MSc, Rebecca Leek, Jordan Zach, Alex Kluiber, Jered Sieren, Heather Baumhauer, Verity McArthur, Dzimitry Kazlouski, Andrew Allen, Tanya Mann, Anastasia Rodionova

PFT QA Core, LDS Hospital, Salt Lake City, UT: Robert Jensen, PhD Biological Repository, Johns Hopkins University, Baltimore, MD: Homayoon Farzadegan, PhD, Stacey Meyerer, Samantha Bragan

Data Coordinating Center and Biostatistics, National Jewish Health, Denver, CO: Douglas Everett, PhD, Carla Wilson, MS, Ruthie Knowles, Amber Powell, Joe Piccoli, Maura Robinson, Margaret Forbes, Martina Wamboldt Epidemiology Core, University of Colorado School of Public Health, Denver, CO: John Hokanson, MPH, PhD, Marci Sontag, PhD, Jennifer Black-Shinn, MPH, Gregory Kinney, MPH

\section{Author details}

${ }^{1}$ Channing Division of Network Medicine, Brigham and Women's Hospital and Harvard Medical School, 181 Longwood Avenue, Boston, MA 02115, USA. ${ }^{2}$ Division of Pulmonary and Critical Care Medicine, Brigham and Women's Hospital and Harvard Medical School, Boston, MA, USA. ${ }^{3}$ Department of Biostatistics, Colorado School of Public Health, Aurora, CO, USA. ${ }^{4}$ Department of Epidemiology, Colorado School of Public Health, Aurora, CO, USA. ${ }^{5}$ Department of Radiology, University of California, San Diego, CA, USA. 'Division of Pulmonary and Critical Care Medicine, University of Michigan Health System, Ann Arbor, MI, USA. ${ }^{7}$ Department of Radiology, Brigham and Women's Hospital and Harvard Medical School, Boston, MA, USA. ${ }^{8}$ Department of Radiology, National Jewish Health, Denver, CO, USA. ${ }^{9}$ Division of Pulmonary and Critical Care Medicine, National Jewish Health, Denver, CO, USA. ${ }^{10}$ Section of Pulmonary and Critical Care Medicine, Temple University, Philadelphia, PA, USA. ${ }^{11}$ Department of Radiology, University of lowa, lowa City, IA, USA. ${ }^{12}$ Division of Pulmonary, Allergy, and Critical Care Medicine, University of Pittsburgh, Pittsburgh, PA, USA.

Received: 8 November 2012 Accepted: 14 March 2013 Published: 8 April 2013

\section{References}

1. Hogg JC, Macklem PT, Thurlbeck WM: Site and nature of airway obstruction in chronic obstructive lung disease. N Engl J Med 1968, 278(25):1355-1360.

2. Han MK, Agusti A, Calverley PM, Celli BR, Criner G, Curtis JL, Fabbri LM, Goldin JG, Jones PW, Macnee W, Make BJ, Rabe KF, Rennard SI, Sciurba FC, Silverman EK, Vestbo J, Washko GR, Wouters EF, Martinez FJ: Chronic 
obstructive pulmonary disease phenotypes: the future of COPD. Am J Respir Crit Care Med 2010, 182(5):598-604.

3. Aberle DR, Adams AM, Berg CD, Black WC, Clapp JD, Fagerstrom RM, Gareen IF, Gatsonis C, Marcus PM, Sicks JD: Reduced lung-cancer mortality with low-dose computed tomographic screening. N Engl J Med 2011, 365(5):395-409.

4. Busacker A, Newell JD Jr, Keefe T, Hoffman EA, Granroth JC, Castro M, Fain S, Wenzel S: A multivariate analysis of risk factors for the air-trapping asthmatic phenotype as measured by quantitative $\mathrm{CT}$ analysis. Chest 2009, 135(1):48-56.

5. Eda S, Kubo K, Fujimoto K, Matsuzawa Y, Sekiguchi M, Sakai F: The relations between expiratory chest $\mathrm{CT}$ using helical $\mathrm{CT}$ and pulmonary function tests in emphysema. Am J Respir Crit Care Med 1997, 155(4):1290-1294.

6. Kubo K, Eda S, Yamamoto H, Fujimoto K, Matsuzawa Y, Maruyama Y, Hasegawa M, Sone S, Sakai F: Expiratory and inspiratory chest computed tomography and pulmonary function tests in cigarette smokers. Eur Respir J 1999, 13(2):252-256.

7. Lee YK, Oh YM, Lee JH, Kim EK, Kim N, Seo JB, Lee SD: Quantitative assessment of emphysema, air trapping, and airway thickening on computed tomography. Lung 2008, 186(3):157-165.

8. Matsuoka S, Kurihara Y, Yagihashi K, Hoshino M, Watanabe N, Nakajima Y: Quantitative assessment of air trapping in chronic obstructive pulmonary disease using inspiratory and expiratory volumetric MDCT. AJR Am J Roentgenol 2008, 190(3):762-769.

9. Mets OM, Murphy K, Zanen P, Gietema HA, Lammers JW, van Ginneken B, Prokop $M$, de Jong PA: The relationship between lung function impairment and quantitative computed tomography in chronic obstructive pulmonary disease. Eur Radiol 2012, 22(1):120-128.

10. O'Donnell RA, Peebles C, Ward JA, Daraker A, Angco G, Broberg P, Pierrou S, Lund J, Holgate ST, Davies DE, Delany DJ, Wilson SJ, Djukanovic R: Relationship between peripheral airway dysfunction, airway obstruction, and neutrophilic inflammation in COPD. Thorax 2004, 59(10):837-842.

11. Mets OM, Buckens CF, Zanen P, Isgum I, van Ginneken B, Prokop M, Gietema HA, Lammers JW, Vliegenthart R, Oudkerk M, van Klaveren RJ, de Koning HJ, Mali WP, de Jong PA: Identification of chronic obstructive pulmonary disease in lung cancer screening computed tomographic scans. JAMA 2011, 306(16):1775-1781.

12. Regan EA, Hokanson JE, Murphy JR, Make B, Lynch DA, Beaty TH, Curran-Everett D, Silverman EK, Crapo JD: Genetic epidemiology of COPD (COPDGene) study design. COPD 2010, 7(1):32-43.

13. Mahler DA, Wells CK: Evaluation of clinical methods for rating dyspnea. Chest 1988, 93(3):580-586.

14. Jones PW, Quirk FH, Baveystock CM, Littlejohns P: A self-complete measure of health status for chronic airflow limitation. The St. George's respiratory questionnaire. Am Rev Respir Dis 1992, 145(6):1321-1327.

15. Rabe KF, Hurd S, Anzueto A, Barnes PJ, Buist SA, Calverley P, Fukuchi Y, Jenkins C, Rodriguez-Roisin R, van Weel C, Zielinski J: Global strategy for the diagnosis, management, and prevention of chronic obstructive pulmonary disease: GOLD executive summary. Am J Respir Crit Care Med 2007, 176(6):532-555.

16. Brusasco V: Spirometric definition of COPD: exercise in futility or factual debate? Thorax 2012, 67(7):569-570.

17. Estepar RS, Washko GG, Silverman EK, Reilly JJ, Kikinis R, Westin CF: Accurate airway wall estimation using phase congruency. Med Image Comput Comput Assist Interv Int Conf Med Image Comput Comput Assist Interv 2006, 9(Pt 2):125-134

18. Hersh CP, Washko GR, Jacobson FL, Gill R, Estepar RS, Reilly JJ, Silverman EK: Interobserver variability in the determination of upper lobe-predominant emphysema. Chest 2007, 131(2):424-431.

19. Gevenois PA, De Vuyst P, de Maertelaer V, Zanen J, Jacobovitz D, Cosio MG, Yernault JC: Comparison of computed density and microscopic morphometry in pulmonary emphysema. Am J Respir Crit Care Med 1996, 154(1):187-192.

20. Nakano Y, Wong JC, de Jong PA, Buzatu L, Nagao T, Coxson HO, Elliott WM, Hogg JC, Pare PD: The prediction of small airway dimensions using computed tomography. Am J Respir Crit Care Med 2005, 171(2):142-146.

21. Hersh CP, Hokanson JE, Lynch DA, Washko GR, Make BJ, Crapo JD, Silverman EK: Family history is a risk factor for COPD. Chest 2011, 140(2):343-350.

22. Kim DK, Jacobson FL, Washko GR, Casaburi R, Make BJ, Crapo JD, Silverman EK, Hersh CP: Clinical and radiographic correlates of hypoxemia and oxygen therapy in the COPDGene study. Respir Med 2011, 105(8):1211-1221.
23. Rambod M, Porszasz J, Make BJ, Crapo JD, Casaburi R: Six-minute walk distance predictors, including CT scan measures, in the COPDGene cohort. Chest 2012, 141(4):867-875.

24. Shaker SB, Stavngaard T, Laursen LC, Stoel BC, Dirksen A: Rapid fall in lung density following smoking cessation in COPD. COPD 2011, 8(1):2-7.

25. Washko GR, Hunninghake GM, Fernandez IE, Nishino M, Okajima Y, Yamashiro T, Ross JC, Estepar RS, Lynch DA, Brehm JM, Andriole KP, Diaz AA, Khorasani R, D'Aco K, Sciurba FC, Silverman EK, Hatabu H, Rosas IO: Lung volumes and emphysema in smokers with interstitial lung abnormalities. N Engl J Med 2011, 364(10):897-906.

26. Wan ES, Hokanson JE, Murphy JR, Regan EA, Make BJ, Lynch DA, Crapo JD, Silverman EK: Clinical and radiographic predictors of GOLD-unclassified smokers in the COPDGene study. Am J Respir Crit Care Med 2011, 184(1):57-63.

27. Newman KB, Lynch DA, Newman LS, Ellegood D, Newell JD Jr: Quantitative computed tomography detects air trapping due to asthma. Chest 1994, 106(1):105-109.

28. Dame Carroll JR, Chandra A, Jones AS, Berend N, Magnussen JS, King GG: Airway dimensions measured from micro-computed tomography and high-resolution computed tomography. Eur Respir J 2006, 28(4):712-720.

29. Han MK, Kazerooni EA, Lynch DA, Liu LX, Murray S, Curtis JL, Criner GJ, Kim V, Bowler RP, Hanania NA, Anzueto AR, Make BJ, Hokanson JE, Crapo JD, Silverman EK, Martinez FJ, Washko GR: Chronic obstructive pulmonary disease exacerbations in the COPDGene study: associated radiologic phenotypes. Radiology 2011, 261(1):274-282.

30. Kim V, Han MK, Vance GB, Make BJ, Newell JD, Hokanson JE, Hersh CP, Stinson D, Silverman EK, Criner GJ: The chronic bronchitic phenotype of COPD: an analysis of the COPDGene Study. Chest 2011, 140(3):626-633.

31. Diaz AA, Come CE, Ross JC, San Jose Estepar R, Han MK, Loring SH, Silverman EK, Washko GR: Association between airway caliber changes with lung inflation and emphysema assessed by volumetric CT scan in subjects with COPD. Chest 2012, 141(3):736-744.

32. Martinez $\mathrm{CH}$, Chen $\mathrm{YH}$, Westgate $\mathrm{PM}$, Liu LX, Murray S, Curtis JL, Make BJ, Kazerooni EA, Lynch DA, Marchetti N, Washko GR, Martinez FJ, Han MK. Relationship between quantitative CT metrics and health status and BODE in chronic obstructive pulmonary disease. Thorax 2012, 67(5):399-406.

33. Vestbo J, Anderson W, Coxson HO, Crim C, Dawber F, Edwards L, Hagan G, Knobil K, Lomas DA, MacNee W, Silverman EK, Tal-Singer R: Evaluation of COPD longitudinally to identify predictive surrogate End-points (ECLIPSE). Eur Respir J 2008, 31(4):869-873.

34. Silverman EK, Vestbo J, Agusti A, Anderson W, Bakke PS, Barnes KC, Barr RG, Bleecker ER, Boezen HM, Burkart KM, Celli BR, Cho MH, Cookson WO, Croxton T, Daley D, DeMeo DL, Gan W, Garcia-Aymerich J, Hall IP, Hansel NN, Hersh CP, Kalsheker N, Kiley JP, Kim WJ, Lambrechts D, Lee SD, Litonjua AA, Lomas DA, London SJ, Nishimura M, et al: Opportunities and challenges in the genetics of COPD 2010: an international COPD genetics conference report. COPD 2011, 8(2):121-135.

doi:10.1186/1465-9921-14-42

Cite this article as: Hersh et al:: Paired inspiratory-expiratory chest CT scans to assess for small airways disease in COPD. Respiratory Research $201314: 42$

\section{Submit your next manuscript to BioMed Central and take full advantage of:}

- Convenient online submission

- Thorough peer review

- No space constraints or color figure charges

- Immediate publication on acceptance

- Inclusion in PubMed, CAS, Scopus and Google Scholar

- Research which is freely available for redistribution 